\title{
Laetisaria fuciformis (Basidiomycota, Corticiaceae), nuevo registro de un parásito fúngico sobre gramíneas en el sur de Chile
}

\section{Laetisaria fuciformis (Basidiomycota, Corticiaceae), new record of a fungal grass parasite from southern Chile}

\author{
Götz Palfner ${ }^{1}$, Alicia Marticorena ${ }^{1} \&$ Marcelo Medina ${ }^{2}$ \\ ${ }^{1}$ Departamento de Botánica, Facultad de Ciencias Naturales y Oceanográficas, Universidad de Concepción, Casilla 160-C, \\ Concepción, Chile \\ ${ }^{2}$ Laboratorio Taxonomía de Malezas, Servicio Agrícola Ganadero SAG, Región de la Araucanía, Francisco Bilbao N \\ 931, Temuco, Chile \\ gpalfner@udec.cl
}

\begin{abstract}
A new record of the fungal grass parasite Laetisaria fuciformis from southern Chile is described and its biology is briefly discussed.
\end{abstract}

Laetisaria fuciformis (McAlpine) Burdsall (Basidiomycota, Corticiaceae) es un parásito fúngico llamativo sobre gramíneas (Poaceae). Dado que puede causar necrosis foliar en especies de interés agrícola, ornamental o comercial como la ballica (Lolium perenne L.), entre otras (Hims et al. 1984), está en la lista de parásitos importantes de praderas y céspedes en varios países del mundo. $\mathrm{Su}$ amplia distribución incluye regiones templadas de ambos hemisferios y se desarrolla con preferencia en praderas pobres en nutrientes y anegadas durante la temporada lluviosa (Stalpers \& Loerakker 1982). El anamorfo es la forma dominante del hongo, y se manifesta como cordones hifales (rizomorfos) ramificados, de color rojo o rosado sobre las hojas del hospedero. Este aspecto llamativo se refleja en su nombre común "hilo rojo" (ingl.: "red thread"). La siguiente descripción está basada en especímenes de $L$. fuciformis encontrados en la IX Región de la Araucanía, la cual, según nuestro conocimiento, representa el primer registro científico de la especie en Chile.

La morfología del hongo fue documentada con una cámara digital Nikon D60 (Nikon, Tokio, Japón). Sus características microscópicas fueron estudiadas bajo un microscopio óptico de campo claro Leitz Dialux (Leitz, Wetzlar, Alemania) con aumento de 1000x en preparaciones en agua y documentadas con una cámara digital Nikon Coolpix 950. Medidas microscópicas fueron tomadas mediante un ocular con escala micrométrica calibrada. Antes de ser depositado en la colección de hongos del Herbario de la Universidad de Concepción (CONC-F), el material fúngico fue deshidratado en una estufa de secado (Heraeus, Alemania) a $40^{\circ} \mathrm{C}$ durante 48 horas.

TAXONOMÍA:

Laetisaria fuciformis (McAlpine) Burdsall, Trans. Br. Mycol. Soc. 72(3): 420, 1979.

Basiónimo: Isaria fuciformis Berkeley, J. Linn. Soc. London, Bot. 13: 155-175, 1873.

(Sinónimos, especies relacionadas y clave de identificación: vea Stalpers \& Loerakker 1982).

DESCRIPCIÓN:

Aspecto macroscópico(Fig. 1a,b): talo(anamorfo) emergiendo de la superficie de hojas necróticas y secas de Lolium sp., filamentoso, ramificado, largo hasta $20 \mathrm{~mm}$, grosor hasta 0,5 $\mathrm{mm}$, color rojo pálido a rosado, de superficie lisa.

Aspecto microscópico (Fig. 1c, d): talo formado por cordones de hifas paralelas, de paredes lisas, hialinas, afibuladas; partes de la superficie del talo colonizadas por una levadura asociada, con celulas subglobosas hasta globosas, hialinas y lisas, de (3,6-) 4,6 (-6,4) × (2,1-) 3,6 (-4,3) $\mu \mathrm{m}$.

Laetisaria fuciformis fue descrita originalmente en su forma anamórfica bajo el nombre Isaria fuciformis por Berkeley (1873) en el sur de Australia, la muestra correspondiente fue recolectada en 1854 sobre una gramínea no identificada. Las numerosas células globosas hasta subglobosas que también pudimos observar sobre la superficie del talo, y que fueron interpretadas como 
conidios por Berkeley (motivo para la asignación del hongo al género Isaria), no corresponden a estructuras propias de L. fuciformis, sino a levaduras asociadas, posiblemente de la especie Cryptococcus laurentii (Stalpers \& Loerakker 1982). McAlpine (1906), junto con detectar este error, logró identificar el teleomorfo y renombró el hongo Hypochnus fuciformis. Sin embargo, el género elegido resultó poco satisfactorio y después de varias asignaciones genéricas alternativas por distintos autores (vea sinónimos en Stalpers \& Loerakker 1982), Burdsall (1979) redefinió la especie y le dio su nombre actual.

Según Stalpers \& Loerakker (1982) y Smith et al. (1988), L. fuciformis tiene distribución amplia, con la mayoría de sus registros en Europa y Norteamérica, prefiriendo zonas templadas y húmedas. Sus hospederos principales pertenecen a la familia Poaceae, particularmente a los géneros Agrostis, Festuca, Lolium y Poa. Típicamente se manifiesta durante la temporada lluviosa en praderas o céspedes sobre suelos de mal drenaje y pobres en nitrógeno. Las hojas afectadas se secan de forma progresiva. Con el avance de la infección se forman manchones secos más o menos circulares en el césped o la pradera que pueden alcanzar un diámetro de hasta varios metros. La parte más llamativa del hongo son los cordones hifales rosados o rojos que se inician en los ápices de las hojas infectadas y que, ramificándose, pueden conectar varias hojas, dispersando la infección de este modo. Estos "hilos rojos" no solamente funcionan como propágulos vegetativos, sino también como esclerocios, siendo muy resistentes a temperaturas extremas y deshidratación, con la capacidad de sobrevivir más de dos años en estado seco. Adicionalmente, se pueden formar manchas rosadas sobre los tallos afectados cuya consistencia flocosa se debe a la formación de grandes cantidades de conidios. El teleomorfo se puede observar sólo rara vez, típicamente sobre las bases de plantas en fase tardía de infección. Consiste de un basidioma efuso, membranoso e inconspicuo que se forma sobre la superficie de las hojas infectadas, generando basidios tetraespóricos, los que aún no ha sido registrado en Chile.
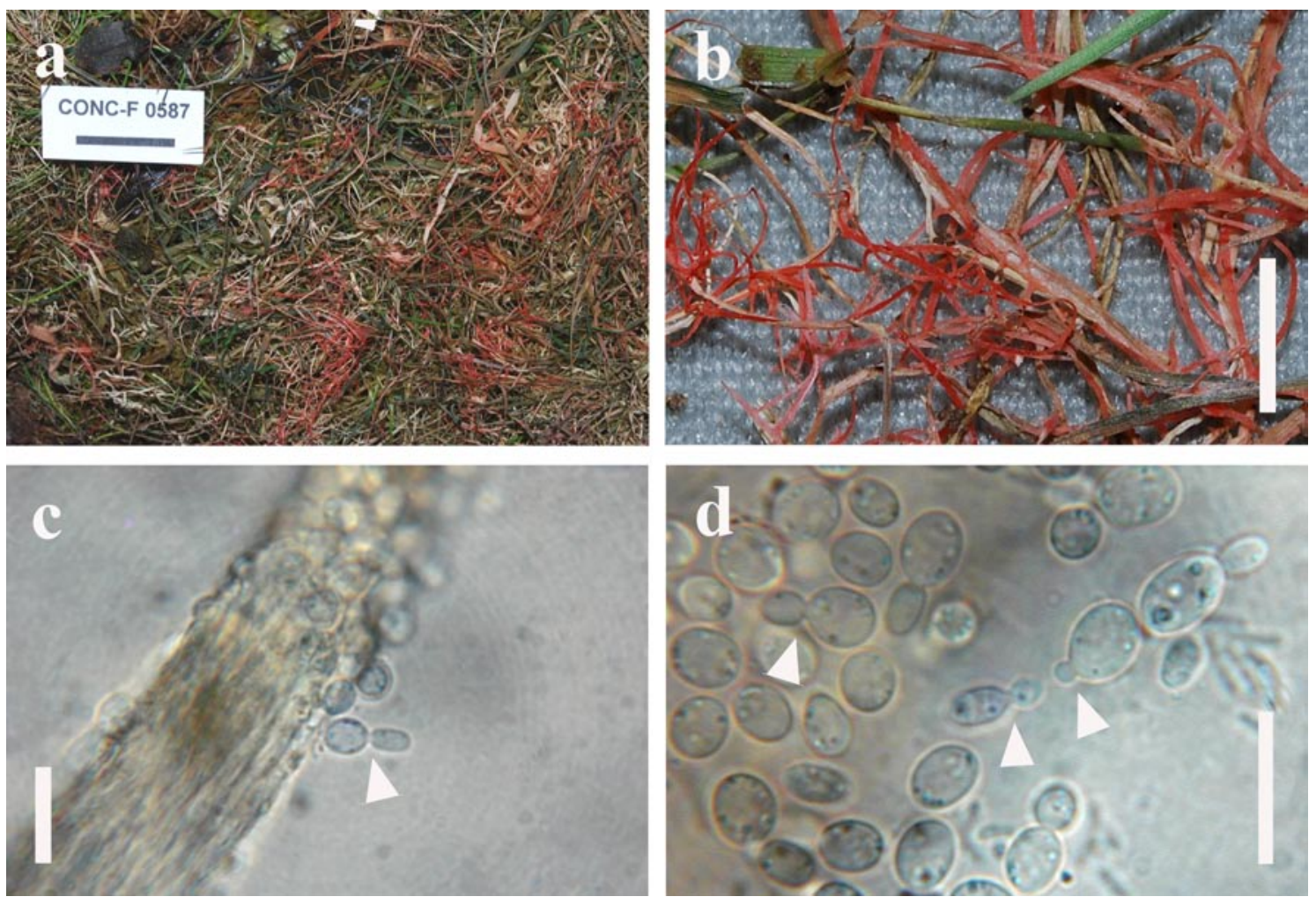

Figura 1. Aspecto macro y microscópico de Laetisaria fuciformis; a: aspecto de pasto afectado in situ, barra = $2 \mathrm{~cm}$; b: acercamiento de talos ramificados emergiendo de hojas infectadas, barra $=1 \mathrm{~cm}$; c: cordón hifal, parcialmente cubierto de células levaduriformes, algunas en proceso de gemación (flecha), barra $=10 \mu \mathrm{m}$; d: colonia de células levaduriformes, algunas en proceso de gemación (flechas), barra $=$ $10 \mu \mathrm{m}$; todas las fotografías de CONC-F0587.

FIGURE 1. Macroscopical and microscopical aspect of Laetisaria fuciformis; a: aspect of infected grass in situ, bar = $2 \mathrm{~cm}$; b: close-up of ramified thalli emerging from infected leaves, bar $=1 \mathrm{~cm}$; c: hyphal strand, partially covered by yeast cells, one of them budding (arrowhead), bar $=10 \mu \mathrm{m}$; d: colony of yeast cells from hyphal strand, some of them budding (arrowheads), bar $=10 \mu \mathrm{m}$; all photos from CONC-F0587. 
El origen geográfico de L. fuciformis sigue siendo un enigma: hacia fines del siglo XIX, el hongo parece haber sido común en zonas de pastoreo en Australia y Gran Bretaña. Curiosamente no existen registros anteriores del hallazgo original en 1854, a pesar de la apariencia llamativa del hongo que seguramente no hubiera pasado inadvertido por los campesinos ingleses y australianos de aquella época (McAlpine 1906). Consecuentemente no se sabe si el hongo fue introducido a Europa desde Australia o viceversa. La supuesta introducción del hongo en Chile parece ser reciente, dado que no se encuentra mencionado en la literatura nacional relevante como la Flora Fungosa Chilena (Mujica et al. 1980), por lo cual un seguimiento de su distribución en el país es recomendable. A pesar de que los daños provocados por L. fuciformis en pastizales, céspedes o canchas deportivas en general son limitados, existen recomendaciones del uso de fungicidas (Hims et al. 1984). Ya que el hongo prolifera mejor en praderas pobres en calcio y nitrógeno, la fertilización adecuada también puede tener un efecto remediador (McAlpine 1906, Smith et al. 1988).

Material EXAMinAdo:

CHILE: Región de la Araucanía, Provincia de Cautín, Comuna de Saavedra, Puerto Domínguez, 3854'01" S, $73^{\circ} 11^{\prime} 11^{\prime \prime} \mathrm{W}$, pradera naturalizada, sobre hojas de Lolium sp., 12-VI-2009, leg. M. Medina, det. A. Marticorena (CONC-F0587).

\section{AGRADECIMIENTOS}

El primer autor agradece el apoyo por el proyecto DIUC 208.111.052-1.0.

\section{BIBLIOGRAFÍA}

Berkeley, M.J. 1873. Australian fungi received principally from Baron F. von Mueller and Dr. R. Schomburgk. Journal of the Linnean Society London, Botany 13: 155-177.

Burdsall, H.H. 1979. Laetisaria (Aphyllophorales, Corticiaceae), a new genus for the teleomorph of Isaria fuciformis. Transactions of the British Mycological Society 72(3): 419-422.

Hims, M.J., C.H. Dickinson \& J.T. Fletcher. 1984. Control of red thread, a disease of grasses caused by Laetisaria fuciformis. Plant Pathology 33:513-516.

McAlpine, D. 1906. A new Hymenomycete - The so-called Isaria fuciformis Berk. Annales Mycologici 4: 541-551.

Mujica, F., C. Vergara \& E. Oehrens. 1980. Flora Fungosa Chilena. $2^{a}$ ed., Editorial Universitaria, Santiago de Chile, $308 \mathrm{pp}$.

Smith, I.M., J. Dunez, D.H. Phillips, S.A. Archer \& R.A. Lelliott (eds.). 1988. European Handbook of Plant Diseases, Blackwell, Oxford, London, 538 pp.

Stalpers, J.A. \& W.M. LoerakKer 1982. Laetisaria and Limonomyces species (Corticiaceae) causing pink diseases in turf grasses. Canadian Journal of Botany 60: 529-537.

Recibido: 16.06 .10

Aceptado: 13.08 .10 